\title{
A unique MRI-pattern in alcohol-associated Wernicke encephalopathy
}

\author{
Ozan E. Eren ${ }^{1} \mathbb{D} \cdot$ Florian Schöberl $^{1} \cdot$ Mattia Campana $^{2} \cdot$ Maximilian Habs $^{1} \cdot$ Julian Conrad $^{1}$
}

Received: 9 July 2020 / Accepted: 31 July 2020 / Published online: 10 August 2020

(c) The Author(s) 2020

Keywords Wernicke encephalopathy $\cdot$ Basal ganglia $\cdot$ Vitamin B1 deficiency $\cdot$ Neuroimaging

\section{Introduction}

Wernicke encephalopathy (WE) due to vitamin-B1 (i.e. thiamine) deficiency is an emergency that might easily be overlooked. The most common underlying cause is vitaminB1 deficiency in the setting of alcohol abuse/addiction. However, there are also many relevant other risk constellations in non-alcoholic patients including inadequate dietary intake (e.g. voluntary starvation, anorexia nervosa, poverty), reduced gastrointestinal absorption (e.g. malignant tumors, after gastric surgery), hyperemesis (e.g. during pregnancy or chemotherapy), decreased hepatic storage or even graftversus-host disease [1-5]. While the treatment is cheap and readily available in the clinical setting, the failure to recognize a thiamine deficiency can have a detrimental effect on the clinical outcome and the patients' quality of life [1]. Therefore, knowledge of the clinical and imaging presentation of Wernicke encephalopathy is crucial for clinical practice.

The classical symptoms are central oculomotor disturbances, gait ataxia as well as disorientation and anterograde amnesia. However, the clinical presentation varies and the classical triad of symptoms is rarely present [1]. The typical imaging findings are T2 and T2-Fluid Attenuation Inversion Recovery (FLAIR)-hyperintense lesions of the mammillary bodies, dorsomedial thalami and periaqueductal gray matter $[1,2,6]$.

Ozan E. Eren

ozan.eren@med.uni-muenchen.de

1 Department of Neurology, University Hospital, LMU, Marchioninistr. 15, Munich 81377, Germany

2 Department of Psychiatry, University Hospital, LMU, Nußbaumstraße 7, Munich 80336, Germany

\section{Case description}

Here we present the case of a 40-year-old female alcoholdependent patient who was assigned from the intensive care unit of an external hospital with the suspected diagnosis of a delir due to long-lasting alcohol consumption ("up to 2 bottles of rum, additionally a few shots of tequila and a couple of beers daily").

On admission the neurological examination revealed severe disorientation regarding her own age, current location and date. Furthermore, the patient was completely amnestic with a score of $0 / 3$ for verbal recall accompanied by pronounced confabulation and suggestibility. She had jerky eye movements with gaze-evoked nystagmus in all directions and severe gait ataxia with repeated falls.

Because of the patients' past medical history with ongoing alcohol consumption for many years and the clinical presentation of a malnourished pre-aged female, intravenous vitamin-B1 replacement $(500 \mathrm{mg} / \mathrm{die})$ was started immediately with WE as the working diagnosis. Laboratory tests were unremarkable except for a slight to moderate elevation of ferritin (397 ng/ml; normal value $15-150 \mathrm{ng} / \mathrm{ml})$, CRP $(1.5 \mathrm{mg} / \mathrm{dl}$; normal value $\leq 1.5 \mathrm{mg} / \mathrm{dl}), \mathrm{LDH}$ (417U/I; normal value $\leq 249 \mathrm{U} / \mathrm{I})$, yGT (119U/I; normal value $\leq 39 \mathrm{U} / \mathrm{I})$ and liver enzymes (GOT 105U/I; normal value $\leq 34 \mathrm{U} / \mathrm{I}$, GPT $58 \mathrm{U} / \mathrm{I}$; normal value $\leq 34 \mathrm{U} / \mathrm{I}$ ). Toxicological screening, cerebrospinal fluid testing and a CT-scan were unremarkable. Unfortunately, vitamin levels were acquired after the first intravenous administration of thiamine.

The MRI-scan revealed a striking pattern with very circumscribed T2-/FLAIR-hyperintensities restricted to the putamen and caput of the caudate nuclei bilaterally (Fig. 1). While we observed the previously described T2-/FLAIRhyperintensities, no corresponding signal alterations were found in the diffusion-weighted imaging sequences (DWI) and apparent diffusion coefficient maps (ADC). Contrast-enhanced sequences were not acquired in our patient. There was fast and 

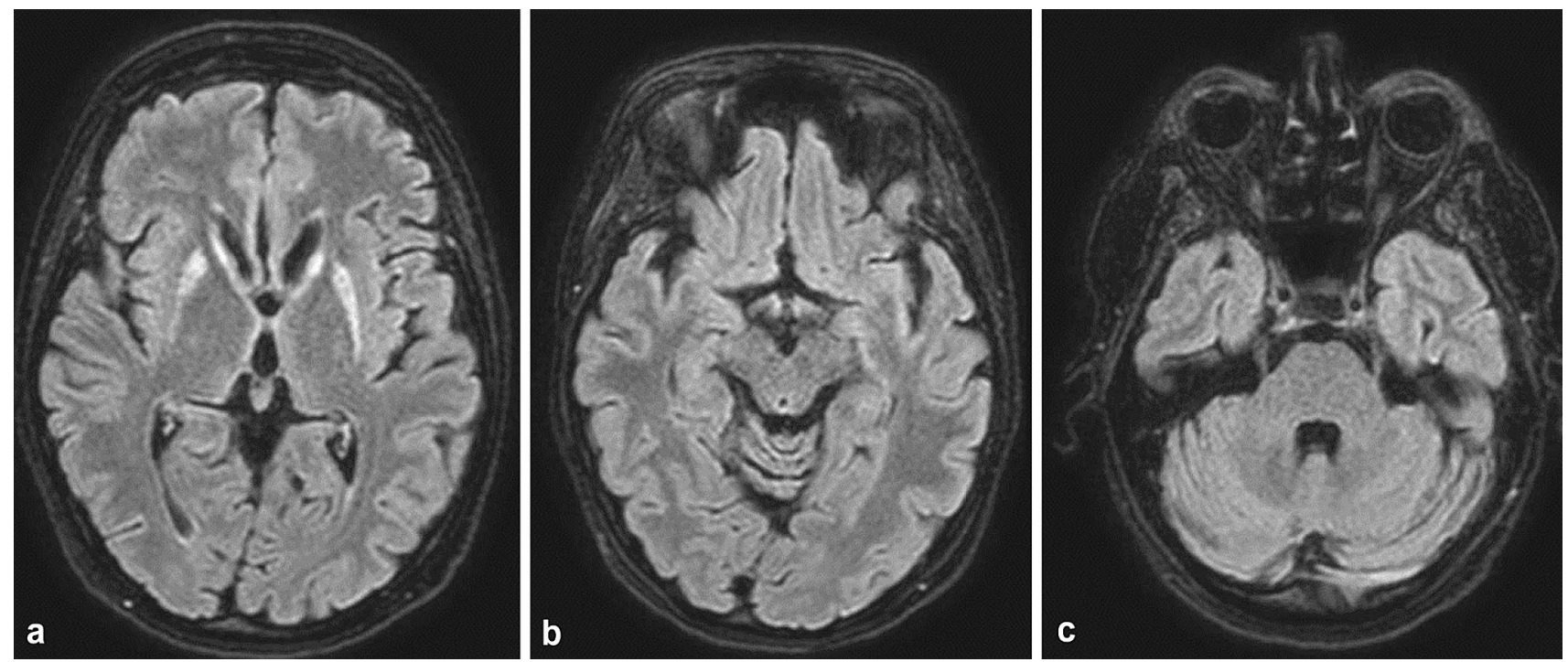

Fig. 1 Axial T2-FLAIR shows bilateral hyperintensities in the putamen and caput nuclei caudati (a), but sparing (b the dorsomedial thalami, periventricular areas around the 3rd ventricle and mesencephalic aqueduct, mammillary bodies)

significant improvement of the severe amnesia as well as the accompanying symptoms after starting vitamin-B1 replacement. A follow-up MRI scan was recommended but could not be carried out due to missing consent from our patient.

\section{Discussion}

Until now, the observed MRI-pattern with exclusive symmetric basal ganglia involvement was only described in children and seemed to discriminate pediatric from adult WE [7]. In a case report, two adult patients with malnutrition in the absence of alcohol dependency also showed basal ganglia involvement, in addition to the affection of the typical regions $[6,8]$. The characteristic clinical picture and fast response to vitamin-B1 replacement along with the history of the patient confirmed the diagnosis of WE. Particularly, since relevant differential diagnoses with a similar MRI-pattern such as hyper-/hypoglycemia, hypoxia, extrapontine myelinolysis or flavivirusassociated encephalitis could be ruled out [9]. Interestingly, in contrast to the MRI-pattern of bilateral basal ganglia hyperintensities, while completely sparing other brain regions usually affected in WE, the clinical symptoms were not only typical for WE, but they also did not include any extrapyramidal signs.

\section{Conclusion}

WE is a clinical diagnosis and already the suspicion should prompt immediate vitamin-B1 replacement. Our case does not only underpin this important practice in suspected WE, but also illustrates the great diversity of MRI-findings.
Acknowledgments Open Access funding provided by Projekt DEAL.

Author contributions OE: drafting/revising the manuscript, planning of clinical diagnostics/diagnostic plan, interpretation of results, making diagnosis and starting treatment. FS: revision of manuscript, interpretation of results, diagnosis confirmation, review of MRI. MC: revision of manuscript, patient treatment, psychiatric assessment. $\mathrm{MH}$ : review of MRI, revision of manuscript. JC: neurological re-examination of the patient, revision of manuscript.

Funding No targeted funding.

\section{Compliance with ethical standards}

Conflict of interest The authors declare that they have no competing interests. OE has received honoraria for consulting within the past three years from Novartis Pharma. FS reports no disclosures. MC reports no disclosures. MH reports no disclosures. JC reports no disclosures.

Ethical approval This article does not contain any studies with human participants besides routine clinical diagnostics by any of the authors.

Informed consent Written informed consent was obtained from the patient for this case report and any accompanying images. A copy of the written consent is available for review by the Editor-in-Chief of this journal.

Open Access This article is licensed under a Creative Commons Attribution 4.0 International License, which permits use, sharing, adaptation, distribution and reproduction in any medium or format, as long as you give appropriate credit to the original author(s) and the source, provide a link to the Creative Commons licence, and indicate if changes were made. The images or other third party material in this article are included in the article's Creative Commons licence, unless indicated otherwise in a credit line to the material. If material is not included in the article's Creative Commons licence and your intended use is not 
permitted by statutory regulation or exceeds the permitted use, you will need to obtain permission directly from the copyright holder. To view a copy of this licence, visit http://creativecommons.org/licenses/by/4.0/.

\section{References}

1. Galvin R, Bråthen G, Ivashynka A et al (2010) EFNS guidelines for diagnosis, therapy and prevention of Wernicke encephalopathy. Eur J Neurol 17:1408-1418. https://doi.org/10.111 1/j.1468-1331.2010.03153.x

2. Zuccoli G, Cruz DS, Bertolini M et al (2009) MR imaging findings in 56 patients with Wernicke encephalopathy: nonalcoholics may differ from alcoholics. Am J Neuroradiol 30:171-176. https ://doi.org/10.3174/ajnr.A1280

3. Di Giuliano F, Picchi E, Scaggiante J et al (2019) Posterior reversible encephalopathy syndrome and Wernicke encephalopathy in patient with acute graft-versus-host disease. Radiol Case Rep 14:971-976. https://doi.org/10.1016/j.radcr.2019.05.024

4. Zuccoli G, Gallucci M, Capellades J et al (2007) Wernicke encephalopathy: MR findings at clinical presentation in twenty-six alcoholic and nonalcoholic patients. Am J Neuroradiol 28:13281331. https://doi.org/10.3174/ajnr.A0544
5. Manzo G, De Gennaro A, Cozzolino A et al (2014) MR imaging findings in alcoholic and nonalcoholic acute Wernicke's encephalopathy: a review. BioMed Res Int. https://doi. org/10.1155/2014/503596

6. Zuccoli G, Siddiqui N, Bailey A, Bartoletti SC (2010) Neuroimaging findings in pediatric Wernicke encephalopathy: a review. Neuroradiology 52:523-529. https://doi.org/10.1007/s0023 4-009-0604-x

7. Zuccoli G, Pipitone N (2009) Neuroimaging findings in acute Wernicke's encephalopathy: review of the literature. Am J Roentgenol 192:501-508. https://doi.org/10.2214/AJR.07.3959

8. Zuccoli G, Cravo I, Bailey A et al (2011) Basal ganglia involvement in Wernicke encephalopathy: report of 2 cases. Am J Neuroradiol 32:E129-E131. https://doi.org/10.3174/ajnr.A2185

9. Bekiesinska-Figatowska M, Mierzewska H, Jurkiewicz E (2013) Basal ganglia lesions in children and adults. Eur J Radiol 82:837849. https://doi.org/10.1016/j.ejrad.2012.12.006

Publisher's Note Springer Nature remains neutral with regard to jurisdictional claims in published maps and institutional affiliations. 